[Agr. Biol. Chem., Vol. 35, No. 7, p. 1084 1091, 1971]

\title{
Studies on a Piscicidal Constituent of Hura crepitans
}

\author{
Part I. Isolation and Characterization of Huratoxin \\ and its Piscicidal Activity ${ }^{\dagger}$
}

\author{
By Kanzo SaKata, ${ }^{*}$ Kazuyoshi Kawazu** and Tetsuo Mitsui \\ Department of Food Science and Technology, \\ Kyoto University, Kyoto \\ Received January 19, 1971
}

\begin{abstract}
Huratoxin, $[\alpha]_{\mathrm{D}}^{28}+55.1\left(c=2.69, \mathrm{CHCl}_{3}\right)$, a piscicidal constituent, was isolated from the sap of Hura crepitans. It was elucidated to have the formula $\mathrm{C}_{34} \mathrm{H}_{48} \mathrm{O}_{8}$ and contain a 1,3 trideca-dienyl, an isopropenyl, a secondary methyl, an $\alpha$-methylcyclopentenone, an epoxide and three hydroxyl (primary, secondary and tertiary) groups. Its piscicidal activity was evaluated to be about 10 times that of rotenone.
\end{abstract}

Hura crepitans L. (Euphorbiaceae) is a tree originally found in the American tropics, which has many thorns on its trunk and is a good store of milky sap. It has long been recognized as a dangerous plant. Ingestion of two or three seeds produces severe emesis and purging. Contact with the plant produces severe skin irritation $^{11}$ in some individuals. The milky sap was known to be a fish poison, ${ }^{2)}$ sometimes in America, an arrow poison.

Studies on the drastic substances of this plant had not yet given any clear-cut result until a haemoagglutinating constituent, crepitine, was

$\dagger$ This report was presented at the 14th Symposium on the Chemistry of Natural Products in Fukuoka, Oct. 29, 1970, by K. Sakata, K. Kawazu and T. Mitsui, Symposium Papers, 227 (1970).

* Present address: Pesticides Synthesis Lab. 3, The Institute of Physical and Chemical Research, Wako, Saitama.

** Present address: Department of Agricultural Chemistry, Okayama University, Okayama.

1) J. M. Kingsbury, "Poisonous Plants of the United States and Canada," Prentice-Hall, Englewood Cliffs, New Jersey, 1964, p. 190.

2) I. H. Burkill, "A Dictionary of the Economic Products of the Malay Peninsula," Vol. I, University Press, Oxford, England, 1935, p. 1223 1224. isolated from this sap by Richet, ${ }^{31}$ which was characterized by Jaffé and Seidl ${ }^{4}$ to be a kind of glycolipoprotein $\left(\mathrm{LD}_{50}\right.$ in mice: $187 \mathrm{mg} / \mathrm{kg}$, agglutination of rabbit blood: $30 \mu \mathrm{g} / \mathrm{ml}$ ).

We isolated a piscicidal constituent from the sap of Hura crepitans, collected in Bolivia. The isolation procedure was guided by piscicidal test. The sap was continuously extracted first with ether and then with methanol. The piscicidal activity was found in both of the ether and methanol extracts, but not in the residue.

The ether extracts were chromatographed on silicic acid-Celite by stepwise elution with benzene containing an increasing ratio of ethyl acetate. The activity was found in the fraction eluted with $22.5 \%$ ethyl acetate in benzene. This fraction was further purified by chromatography on Florisil and by preparative thin-layer chromatography. A piscicidal constituent was obtained in a yield of $c a .0 .008 \%$ of the sap used, and was named "huratoxin."

3) C. Richet, Compt. rend. soc. biol., 66, 763 (1903) [C.A., 4, 5953 (1910)]; ibid., 68, 252 (1905) [C.A., 4, $\left.1987^{3}(1910)\right]$.

4) W. G. Jaffé and D. S. Seidl, Experientia, 25, 891 (1969). 
The active constituent in methanol extracts was proved to be identical with the active substance isolated from the ether extracts.

The piscicidal activity of huratoxin was evaluated, by using killie-fish (Himedaka in Japanese, Oryzias laptipes) as test fish, and the experimental data are shown in Table I. The 24- and 48-hr median tolerance limits estimated by straight line graphical interpolation are listed in Table II, together with those of rotenone,

Table I. Piscicidal Activity of Huratoxin TO KILLIE-FISH

\begin{tabular}{cccc}
$\begin{array}{c}\text { Conc. of } \\
\text { Huratoxin }\end{array}$ & $\begin{array}{c}\text { Number of } \\
\text { test fish } \\
\text { added originally }\end{array}$ & \multicolumn{2}{c}{$\begin{array}{c}\text { Number of } \\
\text { test fish } \\
\text { surviving after }\end{array}$} \\
\hline ppm $(\mu \mathrm{M})$ & & $24 \mathrm{hr}$ & $48 \mathrm{hr}$ \\
$0.0029(0.0050)$ & 5 & 0 & 0 \\
$0.0022(0.0037)$ & 5 & 1 & 0 \\
$0.0016(0.0027)$ & 5 & 1 & 1 \\
$0.0012(0.0020)$ & 5 & 3 & 2 \\
$0.0009(0.0015)$ & 5 & 4 & 5 \\
control & 5 & 5 & 5 \\
\hline
\end{tabular}

Table II. The Median Tolerance limits of Huratoxin, Callicarpone, Rotenone and SODIUM PENTACHLOROPHENOXIDE

\begin{tabular}{|c|c|c|c|c|}
\hline & \multicolumn{4}{|c|}{ Median tolerance limit } \\
\hline & \multicolumn{2}{|c|}{$24 \mathrm{hr}$} & \multicolumn{2}{|c|}{$48 \mathrm{hr}$} \\
\hline & ppm & $\mu \mathrm{M}$ & ppm & $\mu \mathrm{M}$ \\
\hline Huratoxin & 0.0014 & 0.0024 & 0.0011 & 0.0019 \\
\hline Callicarpone & 0.042 & 0.13 & 0.024 & 0.072 \\
\hline Rotenone & 0.013 & 0.033 & 0.012 & 0.030 \\
\hline $\begin{array}{l}\text { Sodium penta- } \\
\text { chlorophenoxide }\end{array}$ & 0.25 & 0.87 & 0.24 & 0.83 \\
\hline
\end{tabular}

callicarpone $^{5)}$ and sodium pentachlorophenoxide for comparison. Huratoxin is about 10 times as toxic as rotenone to killie-fish.

Although huratoxin was not crystallizable, it was proved to be homogeneous by thin-layer chromatography on silica gel $\mathrm{G}$ in various de-

5) K. Kawazu, M. Inaba and T. Mitsui, Agr. Biol. Chem., 31, 494, 498 (1967). veloping solvent systems. It was visualized by characteristic reddish brown when sprayed with the reagent composed of ammonium metavanadate and $50 \%$ sulfuric acid. Huratoxin was proved to consist of carbon, hydrogen and oxygen by the qualitative and elemental analysis.

Huratoxin (l) showed ${ }^{*}$ IR $\nu_{\max } \mathrm{cm}^{-1}: 3500$ $(\mathrm{OH}), 1700(\mathrm{C}=\mathrm{O}), 1680$ and $1638(\mathrm{C}=\mathrm{C})$, and UV $\lambda_{\max } \mathrm{nm}(\varepsilon): 231(28,000)$, and $240(21,000)$ as a shoulder. Its PMR spectrum (Fig. 1) exhibited signals ascribed to $n$-alkyl group (0.92, $3 \mathrm{H}$, perturbed t. and $1.27, c a .10 \mathrm{H}$, broad s.), two methyl groups on double bonds $(1.80,6 \mathrm{H}$, broad s.), terminal methylene (4.92 and 5.04, $1 \mathrm{H}$ each, m.) and other five olefinic protons. The disappearance of signals equivalent to three protons by the addition of $\mathrm{D}_{2} \mathrm{O}$ showed three hydroxyl groups exist in huratoxin. It is noticeable that huratoxin showed carbonyl band at $1700 \mathrm{~cm}^{-1}$ but no prominent band near $1250 \mathrm{~cm}^{-1}$ characteristic for ester function in its IR spectrum. This suggests that no ester function is present in 1 .

Catalytic hydrogenation of $l$ with platinum catalyst in ethanol gave hexahydrohuratoxin (2). The PMR spectrum of 2 , in which a new doublet $(J=7 \mathrm{~Hz})$ equivalent to six protons were observed at $0.95 \mathrm{ppm}$ instead of the signals characteristic for the terminal methylene and the one vinylic methyl indicated the presence of an isopropenyl group in 1 .

On acetylation with acetic anhydride and pyridine $l$ gave diacetylhuratoxin (3), which was reconverted to 1 by treatment with ammonia in methanol. In the PMR spectrum of 3 , the two-proton broad singlet (3.84) observed in that of 1 changed into an $A B$ quartet (3.62 and 4.68) with a large coupling constant $(J=12 \mathrm{~Hz}$ ), and the one-proton singlet in 1 was

* Unless otherwise stated, the UV absorption spectra were taken in ethanol and the PMR spectra in deuteriochloroform at $60 \mathrm{MHz}$. Chemical shifts were expressed in $\mathrm{ppm}$ from tetramethylsilane as internal standard and coupling constant in $\mathrm{Hz}$. Singlet, doublet, double doublet, triplet and multiplet are abbreviated to s., d., d.d., t. and $\mathrm{m}$., respectively. 


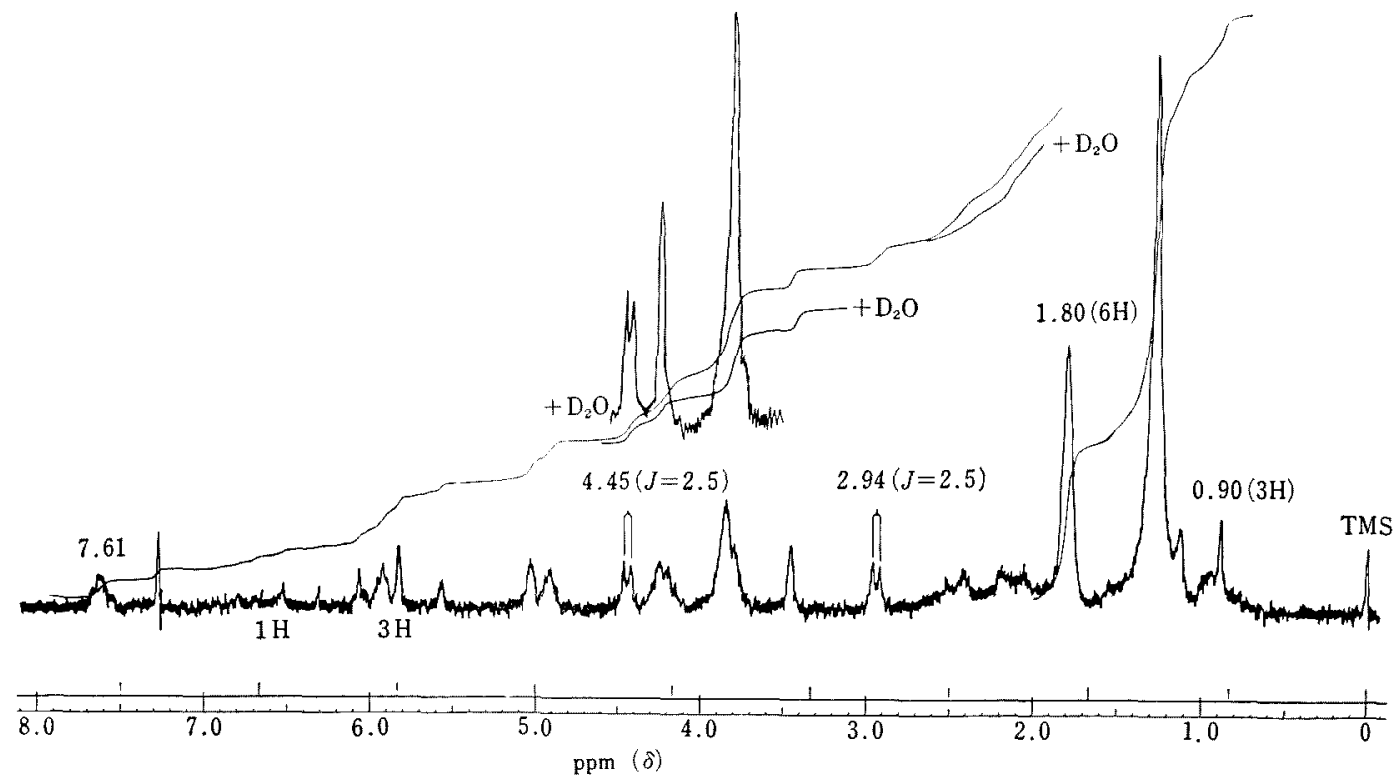

FIG. 1. Proton Magnetic Resonance Spectrum of Huratoxin ( $\left.\mathrm{CDCl}_{3}, 60 \mathrm{MHz}\right)$.

shifted downfield by $1.3 \mathrm{ppm}$ to $5.54 \mathrm{ppm}$. This observation indicates the presence of a primary and a secondary hydroxyl group as depicted (a) and (b). The existence of (b) was confirmed by taking the PMR spectrum of $l$ in $\mathrm{d}_{6}$ DMSO. One hydroxyl proton signal of 3 which was confirmed by the addition of $\mathrm{D}_{2} \mathrm{O}$ pointed to the presence of a tertiary hydroxyl group in 1 .

Hexahydrohuratoxin (2) also provided its diacetate $(4), \operatorname{mp} 62 \sim 62.5^{\circ} \mathrm{C}$, needles, $[\alpha]_{\mathrm{D}}^{17}+68.7^{\circ}$ $\left(c=1.79, \mathrm{CHCl}_{3}\right)$, by acetylation with acetic anhydride and pyridine. It was deacetylated to 2 with ammonia in methanol like diacetylhuratoxin (3). Comparison of the PMR spectra of 2 and 4 also supported the presence of a primary and a secondary hydroxyl group.

Huratoxin (1) and its diacetate (3) are unstable and decomposed on exposure to air. This fact, together with their UV absorption maximum $(231 \mathrm{~nm}, \varepsilon 28,000)$, suggests the existence of a conjugated diene in 1. Di- or tri-substituted diene could be worked out for this diene by application of the Woodward rule to this maximum. In the PMR spectrum of hexahydrohuratoxin (2) the four olefinic proton signals as well as the terminal methylene proton signals had disappeared. This shows that these olefinic protons are attributed to the diene, which is deduced to be di-substituted. In the PMR spectrum of 2 the singlet at $1.27 \mathrm{ppm}$ attributed to polymethylene is remarkably sharpened as compared with that of 1 . On the basis of the foregoing the $n$-alkyl group is anticipated to be connected with the disubstituted diene.

The ethyl acetate solution of 3 was ozonized with two molar equivalents of ozone. The resulting ozonide was reductively degraded by catalytic hydrogenation with platinum catalyst. A volatile aldehyde was captured as its 2,4dinitrophenylhydrazone and identified as formaldehyde. The remaining reaction mixture was concentrated and chromatographed on silicic acid-Celite. From the first eluate a straight chain aldehyde was obtained and identified as $n$-decanal by its mass spectrum and measurement of mixed melting pointed of its 
2,4-dinitrophenylhydrazone.

From the latter fraction was obtained a ketoenal (5). The PMR Spectrum of 5 is similar to that of 3 except the following aspects: the signals ascribed to $n$-alkyl and isopropenyl group were not observed, but an additional acetyl group $(2.30,3 \mathrm{H}$, s.) and an aldehydic proton $(9.75,1 \mathrm{H}$, d.d., $J=5,2.5 \mathrm{~Hz})$. The aldehydic proton is the $\mathrm{X}$ part of an ABX type splitting pattern with two olefinic protons at 6.66 and $6.81 \mathrm{ppm}$. This PMR and UV $\left(\lambda_{\operatorname{mas}}\right.$ nm (s): 212 (shoulder 13,000), 238 (7500)) spectra revealed the presence of an $\alpha, \beta$-unsaturated aldehyde group in 5 . The coupling constant $\left(J_{\mathrm{AB}}=15 \mathrm{~Hz}\right)$ of the ABX type splitting pattern showed the trans-configuration of the double bond. The isopropenyl group was oxidized by ozone to the aforesaid formaldehyde and the additional acetyl group, and the diene to $n$-decanal and the $\alpha, \beta$-unsaturated aldehyde group. In this partial ozonolysis were unequivocally oxidized only the one double bond of the diene and the terminal methylene. This indicates that the partial structure (c) and an isopropenyl group exist in 1 .

As huratoxin $(1)$ was not crystallizing and easily air-oxidized, it was not expected to provide a reliable elemental analytical data. Moreover no molecular ion peak was observed in the mass spectra of $l$ and all of the other derivatives. The ketoenal (5), however, showed its parent peak at m/e 546. By high resolution mass spectrometry the formula of 5 was determined to be $\mathrm{C}_{29} \mathrm{H}_{30} \mathrm{O}_{12}$. On the basis of the fact that the diacetylhuratoxin (3) was unambiguously degraded to the ketoenal (5), ndecanal and formaldehyde on the above mentioned ozonolysis, the molecular formula, $\mathrm{C}_{34} \mathrm{H}_{48} \mathrm{O}_{8}$, was assigned to huratoxin (1). The elemental analysis of diacetyl hexahydrohuratoxin (4) also supported the molecular formula of 1 .

An aldehyde hydrate $(6)$, as well as 5 , was obtained by ozonolysis with three molar equivalents of ozone. Though 6 gave a positive silver mirror reaction, it showed neither al- dehydic proton nor olefinic protons, but a broadened one-proton multiplet at $5.2 \mathrm{ppm}$ which was turned to singlet by the addition of $\mathrm{D}_{2} \mathrm{O}$ in its PMR measurement. The aldehyde hydrate (6) was shown in its PMR spectrum to have two more hydroxyl groups than 5. The mass spectrum of 6 exhibited the highest mass peak at m/e 520 with generation of water vapor. The difference in mass units between the highest mass peaks of 5 and 6 is 26 which corresponds to $\mathrm{C}_{2} \mathrm{H}_{2}$. These evidence clarified that 5 was further oxidized with ozone at the double bond of the $\alpha, \beta$ unsaturated aldehyde to 6 which had a hydrated aldehyde group.

The PMR spectrum of huratoxin (I) exhibited a characteristic one-proton multiplet at $7.61 \mathrm{ppm}$. The IR and UV spectra of $l$ suggested the absence of benzene or furan ring. The spindecoupling experiments disclosed that the one-proton multiplet at $7.61 \mathrm{ppm}$ was related not only to the one-proton multiplet at $3.84 \mathrm{ppm}$ with a coupling constant of $2.0 \mathrm{~Hz}$, but also to the broad singlet at $1.80 \mathrm{ppm}$ assigned to a vinylic methyl group. This fact and the other spectroscopic characteristics of $2\left(\lambda_{\max } \mathrm{nm}(\varepsilon): 240(7200), \nu_{\max } \mathrm{cm}^{-1} 1700,1635\right)$ which are in good agreement with those of $\alpha$-methylcyclopentenone compounds illustrated in Fig. 2 are suggestive of the presence of $\alpha-$ methylcyclopentenone structure. This partial structure (d) was confirmed as follows:

Huratoxin (1) absorbed four molar equivalents of hydrogen over a large amount of platinum catalyst in ethanol, yielding octahydrohuratoxin which gave triacetyl octahydrohuratoxin (7) by acetylation with acetic anhydride and pyridine. It showed no UV absorption maximum over $210 \mathrm{~nm}(\varepsilon 1400)$. In its PMR spectrum the characteristic one-proton multiplet (7.61) observed in $I$ had shifted to the ordinary olefinic region (5.71), and appeared an additional acetoxyl methyl (2.02) and a proton (5.55) attached to the carbon atom bearing this acetoxyl group. Moreover the vinylic methyl suffered a high field shifts by $0.2 \mathrm{ppm}$. Its 


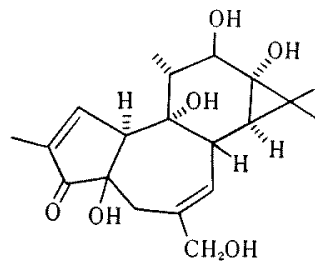

$1698,1640 \mathrm{~cm}^{-1}{ }^{6)}$ $235 \mathrm{~nm}(\varepsilon 5200)$

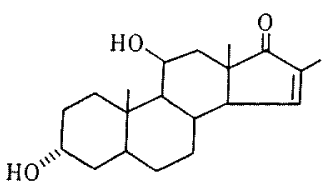

$1701 \mathrm{~cm}^{-1}{ }^{71}$ $243 \mathrm{~nm}(\varepsilon 6850)$

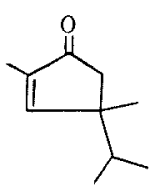

$1707 \mathrm{~cm}^{-1}{ }^{81}$ $230 \mathrm{~nm}$

Frg. 2.

IR spectrum showed the absence of the strong absorption bands due to the enone structure $\left(1700,1635 \mathrm{~cm}^{-1}\right)$. On lithium and liquid ammonia reduction diacetyl hexahydrohuratoxin (4) afforded a cyclopentanone (8) which showed no absorption maximum over $210 \mathrm{~nm}(\varepsilon 1000)$ and a carbonyl absorption band at $1755 \mathrm{~cm}^{-1}$.<smiles>CC(O)C(C)(C)C</smiles><smiles>C=CC=CCCCC=CC(=C)C</smiles>

(c)<smiles>CC1=CC2C=C(C)C1C2</smiles>

(d)<smiles>CC1OC1(C)C</smiles><smiles>CCC(C)C</smiles>

(e)

FIG. 3.
Diacetyl hexahydrohuratoxin (4) reacted with hydrogen bromide in acetic acid to yield its bromohydrin, which could be reconverted to

6) E. Hecker, H. Bartsch, H. Bresch, M. Gschwendt, E. Härle, G. Kreibich, H. Kubinyi, H. U. Schairer, Ch. Szczepanski and H. W. Thielmann, Tetrahedron Letters, 3165 (1967); L. Crombie, M. L. Games and D. J. Pointer, J. Chem. Soc. (C), 1968, 1347.

7) D. Taub, R. D. Hoffsommer, H. L. Slates, C. H. Kuo and N. L. Wendler, J. Am. Chem. Soc., 82, 4012 (1960).

8) W. E. Doering, M. R. Willcott, III and M. Jones, Jr., J. Am. Chem. Soc., 84, 1224 (1962).
4 by being heated in aqueous ethanol. This fact suggests the presence of 1,2-oxide ring and this easy reversibility is worth noting. Similarly, triacetyl octahydrohuratoxin (7) gave the corresponding bromohydrin (9), the PMR spectrum of which exhibited a one-proton doublet at $4.97 \mathrm{ppm}(J=10 \mathrm{~Hz})$, instead of oneproton broad singlet at $3.36 \mathrm{ppm}$. The partial structure (e) was inferred to exist in 1 .

The PMR spectra of almost all derivatives of huratoxin exhibited a three-proton doublet $(J=6 \sim 7 \mathrm{~Hz})$ at about $1.0 \mathrm{ppm}$. This indicates the presence of a secondary methyl group in 1.

On the basis of the foregoing, it is argued that $I$ should have all the functional groups illustrated in Fig. 3.

\section{EXPERIMENTAL}

Isolation of huratoxin. The milky sap of Hura crepitans was collected in the southern part of Bolivia. The isolation procedure was guided by the killie-fish bioassay. ${ }^{5}$ A test solution was prepared by adding an acetone solution $(0.5 \mathrm{ml})$ of material to be tested into aerated water $(150 \mathrm{ml})$.

The sap $(10 \mathrm{~kg})$ was continuously extracted with ether in a continuous extractor, and the extract was concentrated to a brown residue weighing $165 \mathrm{~g}$. A part $(4 \mathrm{~g})$ of this residue was adsorbed on silicic acid $(20 \mathrm{~g})$ and chromatographed on silicic acid (150 g)Celite $545(300 \mathrm{~g})$. Each eluant (1 liter) consisted of benzene and ethyl acetate, and the ethyl acetate concentration was increased stepwise $(0,10,15,20,22.5$, $30 \%$ ). The piscicidal activity was found in the fraction eluted with $22.5 \%$ ethyl acetate in benzene. This 
fraction was further chromatographed on Florisil 70 times as much as the sample, and eluted stepwise with benzene containing an increasing ratio ( $50^{\circ}$ step) of ethyl acetate. Then huratoxin could be obtained in nearly pure state. If further purification was needed, it could be purified by silicic acid column or preparative thin-layer chromatography (benzene-ethyl acetate, $1: 1$ ). Huratoxin (1) showed a single spot on silica gel G(E. Merck, $0.25 \mathrm{~mm}$ thick) thin-layer chromatography using various developing solvent systems [benzene-ethyl acetate $(1: 1)(R f 0.5)$, chloroform-ethyl acetate $(1: 1)(R f 0.5)$, benzene-ether $(1: 2)(R f 0.5)$, benzene-acetone $(5: 1)(R f 0.6)]$, but tailing on aluminum oxide $G$. Visualization of the spot was effected by spraying with a solution of ammonium metavanadate $(2.0 \mathrm{~g})$ in $50 \%$ sulfuric acid $(50 \mathrm{ml})$ (characteristic reddish brown spot) or $5 \%$ potassium permanganate in water. Huratoxin (1): glassy resin, $U \lambda_{\max } n m(\varepsilon)$ : 231 (28,000), shoulder $240(21,000)$; IR $\nu_{\max }\left(\mathrm{CCl}_{4}\right)$ $\mathrm{cm}^{-1}: 3500(\mathrm{OH}), 1700(\mathrm{C}=\mathrm{O}), 1680,1638(\mathrm{C}=\mathrm{C})$; PMR, see Fig. 1.

Piscicidal activity. Oryzias laptipes (killie-fish, himedaka in Japanese) averaging $350 \mathrm{mg}$ in weight and $3 \sim$ $3.5 \mathrm{~cm}$ in length were used as the test fish, which were not fed for two days before they were used in a test. As the test containers $200 \mathrm{ml}$ beakers served, in which $150 \mathrm{ml}$ of water was kept. The water must be aerated by means of an air-pump for a few hours. An acetone solution $(0.5 \mathrm{ml})$ of a test compound of a known concentration was added with vigorous stirring. Five test fish were introduced to the test solution. The solution prepared by adding only $0.5 \mathrm{ml}$ of acetone served as control. Fish having died during the test were immediately removed from the solution and those which have been surviving in each test container were observed and recorded exactly $24 \mathrm{hr}$ and $48 \mathrm{hr}$ after their introduction. The experimental data are listed in Table I. The median tolerance limits were estimated by a straight-line graphical interpolation using survival percentages at two successive concentration of the test series which were lethal to more than half and to less than half of the test fish. The experimental data for toxicity of callicarpone, rotenone and sodium pentachlorophenoxide to the killie-fish are listed for comparison with that of huratoxin in Table II. But the test condition is different, that is, the test solution in the case of callicarpone etc. are composed of 10 liter of water and an acetone solution $(1 \mathrm{ml})$ of a test compound of a known concentration (in the case of sodium pentachlorophenoxide, methanol solution was used).
Hexahydrohuratoxin (2). A mixture of $\mathrm{PtO}_{2}(10 \mathrm{mg})$ and ethanol (12 $\mathrm{ml})$ was prehydrogenated until no further uptake of hydrogen occurred. A solution of huratoxin $(73.0 \mathrm{mg})$ in ethanol $(2 \mathrm{ml})$ was added and the hydrogenation was continued at atomospheric pressure and room temperature until 3 molar equivalents of hydrogen was absorbed $(40 \mathrm{~min}$ ). The catalyst was filtered off and the filtrate was evaporated to yield a colorless resinous matter $(71 \mathrm{mg})$. It was chromatographed on a silicic acid-Celite column (benzeneethyl acetate) to yield $2(68 \mathrm{mg})$ : UV $\lambda_{\max } \mathrm{nm}(\varepsilon): 242$ (7200); IR $\nu_{\max }\left(\mathrm{CCl}_{4}\right) \mathrm{cm}^{-1}: 3550(\mathrm{OH}), 1700(\mathrm{C}=\mathrm{O})$, $1635(\mathrm{C}=\mathrm{C})$; PMR $\delta 0.92(3 \mathrm{H}$, perturbed t. $), 0.92(6 \mathrm{H}$, d., $J=7 \mathrm{~Hz}), 1.14(3 \mathrm{H}, \mathrm{d} ., J=6 \mathrm{~Hz}), 1.27$ (s., polymethylene), $1.80(3 \mathrm{H}, \mathrm{m}),. 2.80(1 \mathrm{H}, \mathrm{d} ., J=2.5 \mathrm{~Hz})$, $3.48(1 \mathrm{H}$, s. $), 3.74(1 \mathrm{H}, \mathrm{m}),. 3.80(2 \mathrm{H}$, broad s.), 4.24 (1H, s.), 4.36 (1H, d., $J=2.5 \mathrm{~Hz}), 7.60$ (1H, m.).

Diacetylhuratoxin (3). Acetylation of huratoxin $(268 \mathrm{mg})$ with acetic anhydride and pyridine in a usual manner furnished $3(260 \mathrm{mg})$ after chromatography on silicic acid-Celite $545(1: 1)$ (benzene-ethyl acetate); UV $\lambda_{\max } \mathrm{nm}(\varepsilon): 231(28,000) ; \mathrm{IR} \nu_{\max }\left(\mathrm{CCl}_{4}\right) \mathrm{cm}^{-1}: 3580$ $(\mathrm{OH}), 1760,1746,1710(\mathrm{C}=\mathrm{O}), 1671,1632(\mathrm{C}=\mathrm{C})$; PMR $\delta 0.92(3 \mathrm{H}$, perturbed t.), $1.15(3 \mathrm{H}, \mathrm{d} ., J=6 \mathrm{~Hz})$, 1.27 (s., polymethylene), $1.77(3 \mathrm{H}$, broad s.), 1.81 (3H, m.) $, 2.03,2.20(3 \mathrm{H}$ each, s. $), 3.02(1 \mathrm{H}, \mathrm{d} ., J=$ $2.5 \mathrm{~Hz}), 3.09(1 \mathrm{H}$, s., $\mathrm{OH}), 3.38(1 \mathrm{H}, \mathrm{s}), 3.62(1 \mathrm{H}$, d., $J=12 \mathrm{~Hz}), 3.95(1 \mathrm{H}, \mathrm{m}),. 4.43(1 \mathrm{H}, \mathrm{d} ., J=2.5 \mathrm{~Hz})$, $4.68(1 \mathrm{H}, \mathrm{d} ., J=12 \mathrm{~Hz}), 4.92(1 \mathrm{H}, \mathrm{m}),. 5.04(1 \mathrm{H}, \mathrm{m}$.$) ,$ 5.54 (1H, s.), $5.6 \sim 6.7(4 \mathrm{H}), 7.52(1 \mathrm{H}, \mathrm{m}$.$) .$

Diacetyl hexahydrohuratoxin (4). Hexahydrohuratoxin (2) $(20 \mathrm{mg})$ was acetylated with acetic anhydride $(0.5 \mathrm{ml})$ in pyridine $(0.5 \mathrm{ml})$ at room temperature overnight. The reaction mixture was poured onto ice-water and extracted with ether. The ether layer was washed with dil. $\mathrm{HCl}$, dil. $\mathrm{Na}_{2} \mathrm{CO}_{3}$ and water saturated with $\mathrm{NaCl}$, dried over anhydrous sodium sulfate, and then the solvent was evaporated. The residue was purified with preparative thin-layer chromatography (benzeneethyl acetate, $2: 1)$ to yield $4(20 \mathrm{mg})$. It was crystallized from $85 \%$ ethanol: $\mathrm{mp} 62 \sim 62.5^{\circ} \mathrm{C}$ (needles); $[\alpha]_{\mathrm{D}}^{17}+68.7^{\circ}\left(c=1.79, \quad \mathrm{CHCl}_{3}\right) ; \mathrm{UV} \lambda_{\max } \mathrm{nm}(\varepsilon): 240$ (9500); IR $\nu_{\text {max }}\left(\mathrm{CCl}_{4}\right) \mathrm{cm}^{-1}: 3500(\mathrm{OH}), 1760,1727$, $1703(\mathrm{C}=\mathrm{O}), 1632(\mathrm{C}=\mathrm{C}), 1240(-\mathrm{O}-\mathrm{C}=\mathrm{O})$; PMR $\delta 0.92(3 \mathrm{H}$, perturbed t. $), 0.93(6 \mathrm{H}, \mathrm{d} ., J=6 \mathrm{~Hz}), 1.14$ ( $3 \mathrm{H}$, d., $J=6 \mathrm{~Hz}$ ), 1.27 (s., polymethylene), $1.77(3 \mathrm{H}$, m.), $2.05,2.20$ (3H each, s.), 2.88 ( $1 \mathrm{H}, \mathrm{d} ., J=2.5 \mathrm{~Hz})$, $3.05(\mathrm{OH}), 3.36(1 \mathrm{H}, \mathrm{s}), 3.60(1 \mathrm{H}$, d., $J=12 \mathrm{~Hz})$, $3.88(\mathrm{lH}, \mathrm{m}),. 4.32(\mathrm{IH}, \mathrm{d} ., J=2.5 \mathrm{~Hz}), 4.69(1 \mathrm{H}, \mathrm{d}$, 
$J=12 \mathrm{~Hz}), 5.52(1 \mathrm{H}, \mathrm{s.}), 7.49(1 \mathrm{H}, \mathrm{m}$.$) . Found: C,$ $67.2 ; \mathrm{H}, 8.8$. Calcd. for $\mathrm{C}_{38} \mathrm{H}_{58} \mathrm{O}_{10}: \mathrm{C}, 67.63 ; \mathrm{H}$, $8.86 \%$.

Ozonolysis of diacetylhuratoxin (3). A solution of diacetylhuratoxin (3) $(200 \mathrm{mg})$ in ethyl acetate $(10 \mathrm{ml})$ was cooled to $-70^{\circ} \mathrm{C}$ with dry ice and ethanol, and treated with an ethyl acetate solution of 2 molar equivalents of ozone. Prehydrogenated platinum catalyst $(50 \mathrm{mg})$ was added into the reaction mixture and hydrogenation was carried out at room temperature until the reaction mixture showed negativity against potassium iodide-starch test. Nitrogen gas was passed through the reaction mixture and volatile aldehyde was trapped as its 2,4-dinitrophenylhydrazone. It was identified as formaldehyde by its IR spectrum and measurement of mixed melting point with an authentic sample. The remaining reaction mixture was evaporated and chromatographed on silicic acid (15 g)-Celite $545(30 \mathrm{~g})$ by stepwise elution with benzene containing an increasing ratio of ethyl acetate. The first eluate was further chromatographed on silicic acid to yield $n$-decanal $(25 \mathrm{mg})$. Identity with an authentic sample was established by its mass and PMR spectra and melting point of its 2,4-dinitrophenylhydrazone. The latter eluate ( 309 , ethyl acetate in benzene) was purified by preparative thin-layer chromatography (benzene-ethyl acetate, $1: 1$ ) to yield a ketoenal (5) (102 mg): UV $\lambda_{\max } \mathrm{nm}(\varepsilon): 212$ (sh. 13,000), 238 (7500); IR $\nu_{\max }\left(\mathrm{CHCl}_{3}\right) \mathrm{cm}^{-1}: 3570(\mathrm{OH}), 1760 \sim 1738,1705$ $(\mathrm{C}=\mathrm{O}), 1635(\mathrm{G}=\mathrm{C})$; PMR ô $1.15(3 \mathrm{H}, \mathrm{d} ., J=6.5 \mathrm{~Hz})$, $1.78(3 \mathrm{H}$, d.d., $J=2.3,1.0 \mathrm{~Hz}), 2.02,2.20,2.30(3 \mathrm{H}$ each, s. $), 3.10(1 \mathrm{H}$, d., $J=2.5 \mathrm{~Hz}), 3.20(\mathrm{OH}), 3.41$ $(\mathrm{HH}, \mathrm{s}),. 3.66(\mathrm{lH}, \mathrm{d} ., J=12 \mathrm{~Hz}), 3.97$ (1H, m.), 4.66 ( $1 \mathrm{H}, \mathrm{d} ., J=12 \mathrm{~Hz}), 4.86(1 \mathrm{H}, \mathrm{d} ., J=2.5 \mathrm{~Hz}), \quad 5.56$ ( $1 \mathrm{H}, \mathrm{s}$ ), 6.66 (1H, d.d., $J=15,5.0 \mathrm{~Hz}), 6.81$ (1H, d.d., $J=15,2.5 \mathrm{~Hz}), 7.47(1 \mathrm{H}, \mathrm{m}),. 9.57(1 \mathrm{H}, \mathrm{d} . \mathrm{d} ., J=5.0$ $2.5 \mathrm{~Hz}$ ); high-resolution mass spectrum $\mathrm{M}^{+} 5+6.178$ (Calcd. 546.173 for $\mathrm{C}_{27} \mathrm{H}_{30} \mathrm{O}_{12}$ ); MS $m_{i}^{\prime} e$ (relative intensity) $\mathrm{M}-546(0.3), 503(0.7), 443(0.2), 426(0.2)$, $413(0.1), \quad 403(0.3), \quad 343(1.0), \quad 301(1.5), \quad 283(3.8)$, $255(3.2), 243(1.5), 229(2.5), 83(18), 69(9.0), 60(11)$, $55(20), 43(100), 28(29)$.

When three molar equivalents of ozone was introduced into the ethyl acetate solution of diacetylhuratoxin (3), an aldehyde hydrate (6) was obtained as well as the ketonal (5): UV $\lambda_{\max } \mathrm{nm}(\varepsilon): 240.5$ (7000); IR $\nu_{\max }\left(\mathrm{CHCl}_{3}\right) \mathrm{cm}^{-1}: 3570(\mathrm{OH}), 1760 \sim 1740,1708(\mathrm{C}=$ O), $1632(\mathrm{C}=\mathrm{C})$; PMR o $1.18(3 \mathrm{H}, \mathrm{d} ., J=6.5 \mathrm{~Hz}), 1.78$ $(3 \mathrm{H}, \mathrm{m}), 2.03,2.20,.2.32(3 \mathrm{H}$ each, s. $), 3.10(1 \mathrm{H}$, m.), $3.22(\mathrm{OH}), 3.40(1 \mathrm{H}, \mathrm{s}),. 3.66(1 \mathrm{H}, \mathrm{d} ., J=12 \mathrm{~Hz})$,
$3.99(1 \mathrm{H}, \mathrm{m}),. 4.66(1 \mathrm{H}, \mathrm{d} ., J=12 \mathrm{~Hz}), 4.83(1 \mathrm{H}, \mathrm{m}$.$) ,$ $5.2\left(1 \mathrm{H}\right.$, broad m., $\left.+\mathrm{D}_{2} \mathrm{O} \rightarrow \mathrm{s}.\right), 5.56(1 \mathrm{H}, \mathrm{s}),$. $(1 \mathrm{H}, \mathrm{m}$.$) ; MS m / e: \mathrm{M}^{+}-18520(0.4), 477(0.5), 460(0.4)$, $417(1.0), 400(1.6), 387(0.7), 371(0.7), 357(0.8), 346$ $(1.5), 343(1.6), 337(1.6), 301(2.5), 283(5.1), 261(11)$, $255(7.4), 243(3.7), 229(3.7), 165(3.7), \quad \mathrm{I} 51(3.8), 123$ $(5.5), 95(5.0), 71(5.0), 69(7.5), 55(7.5), 43(100), 28(8.0)$.

Triacetyl octahydrohuratoxin (7). A solution of huratoxin (1) $(90 \mathrm{mg})$ in ethanol $(2 \mathrm{ml})$ was added to a prehydrogenated mixture of $\mathrm{PtO}_{2}(30 \mathrm{mg})$ in ethanol $(20 \mathrm{ml})$ was hydrogenated at atmospheric pressure and room temperature until 4 molar equivalents of hy. drogen was consumed ( $2 \mathrm{hr}$ ). The catalyst was filtered off and the ethanol solution was evaporated to yield a colorless residue $(89 \mathrm{mg})$. It was chromatographed on a silicic acid-Celite column (benzene-ethyl acetate) to yield octahydrohuratoxin $(71 \mathrm{mg})$, which gave triacetyl octahydrohuratoxin (7) (73 $\mathrm{mg}$ ) by acetylation with acetic anhydride-pyridine at room temperature; UV $\lambda$ end $\mathrm{ab} .\left(\varepsilon_{210} 1400\right)$; IR $\nu_{\mathrm{max}}\left(\mathrm{CCl}_{4}\right) \mathrm{cm}^{-1}: 3590(\mathrm{OH})$, $1750(\mathrm{C}=\mathrm{O}$, broad $), 1228(-\mathrm{O}-\mathrm{C}=\mathrm{O})$; PMR $\delta 0.90$ $(3 \mathrm{H}$, perturbed t. $), 0.92(6 \mathrm{H}, \mathrm{d} ., J=6 \mathrm{~Hz}), 1.18(3 \mathrm{H}$, d., $J=6 \mathrm{~Hz}), 1.27$ (s., polymethylene), $1.60(3 \mathrm{H}, \mathrm{m}$.$) ,$ $2.02,2.04,2.14$ (3H each, s.), 2.84 (1H, s., OH), $2.86(1 \mathrm{H}, \mathrm{d} ., J=2.5 \mathrm{~Hz}), 3.36(1 \mathrm{H}, \mathrm{s.}), 3.50(1 \mathrm{H}, \mathrm{d}$. $J=12 \mathrm{~Hz}), 4.30(1 \mathrm{H}, \mathrm{d} ., J=2.5 \mathrm{~Hz}), 4.56(1 \mathrm{H}, \mathrm{d} ., J=$ $12 \mathrm{~Hz}), 5.56(1 \mathrm{H}, \mathrm{s}),. 5.64(1 \mathrm{H}, \mathrm{m}),. 5.71(1 \mathrm{H}, \mathrm{m}$.$) .$

Lithium-liquid ammonia reduction of diacetyl hexahydro. huratoxin (4). Liquid ammonia (ca. $10 \mathrm{ml}$ ) was trapped by introducing ammonia gas into a vessel cooled to $-70^{\circ} \mathrm{C}$ with dry ice and ethanol, and lithium metal was thrown into it. The lithium metal dissolved and the solution became bluish. Dry ether solution of diacetyl hexahydrohuratoxin (4) $(160 \mathrm{mg})$ was added dropwise. When the bluish color had disappeared, more lithium metal was added until the solution turned faint blue. Ammonium chloride (ca. $100 \mathrm{mg}$ ) was added and the reaction mixture was kept at room temperature to disperse ammonia. Then, large amounts $(200 \mathrm{ml})$ of ether was added and the insoluble matter was washed thoroughly with ether and filtered off. The ether layer was washed with water, dried over anhydrous sodium sulfate, and concentrated to yield resinous matter $(150 \mathrm{mg})$. It was acetylated with acetic anhydride-pyridine, and chromatographed on a silicic acid $(8 \mathrm{~g})$-Celite $545(8 \mathrm{~g})$ column by stepwise elution with benzene containing an increasing ratio of ether. The fraction eluted with $15 \%$ ether in benzene afforded a cyclopentanone $(8)(20 \mathrm{mg})$; UV hend ab. ( $\left.\varepsilon_{210} 1000\right)$; 
IR $\nu_{\max }\left(\mathrm{CCl}_{4}\right) \mathrm{cm}^{-1}: 3580(\mathrm{OH}), 1760,1755,1746(\mathrm{C}=$ O), 1240, 1120, 1045; PMR $\delta 0.90$ (3H, perturbed t.), $0.92(6 \mathrm{H}, \mathrm{d}, J=6 \mathrm{~Hz}), 1.27$ (s., polymethylene), 2.17 , $2.19(3 \mathrm{H}$ each, s. $), 2.92(1 \mathrm{H}$, d., $J=2 \mathrm{~Hz}), 3.08(1 \mathrm{H}$, s., $\mathrm{OH}), 3.31$ (1H, s.), 3.50 (1H. m.), $3.54(1 \mathrm{H}$, d., $J=12 \mathrm{~Hz}), 4.28(1 \mathrm{H}, \mathrm{d} ., J=2 \mathrm{~Hz}), 4.62(1 \mathrm{H}, \mathrm{d} ., J=$ $12 \mathrm{~Hz}), 5.39(1 \mathrm{H}, \mathrm{s.})$

Bromohydrin (9) of t riacetyl octahyd rohu ratoxin (7). To a solution of 7 (40 $\mathrm{mg})$ in acetic acid $(1.2 \mathrm{ml})$ was added dropwise a solution of $470^{\circ} \dot{o}$ hydrobromic acid $(0.7 \mathrm{ml})$ in acetic acid $(0.7 \mathrm{ml})$. The reaction mixture was kept at $10 \sim 15^{\circ} \mathrm{C}$ for $1 \mathrm{hr}$ and evaporated in vacuo under $30^{\circ} \mathrm{C}$. The residue was chromatographed on silicic acid (2 g)-Celite $545(2 \mathrm{~g})$ by stepwise elution with $n$-hexane containing an increasing ratio of ether. From the fraction eluted with $40 \%$ ether in $n$-hexane was obtained a bromohydrin (9) (27 mg); positive to
Beilstein test; UV $\lambda_{\text {end } a b} \cdot\left(\varepsilon_{210} 3500\right)$; IR $\nu_{\max }\left(\mathrm{CCl}_{4}\right)$ $\mathrm{cm}^{-1}$ : $3590(\mathrm{OH}), 1765 \sim 1735(\mathrm{C}=\mathrm{O}), 1630(\mathrm{C}=\mathrm{C}$, broad), I225 (-O-C=O), 1075, 1030, 895; PMR $\delta$ 0.92 (3H, m.), $0.94(6 \mathrm{H}$, d., $J=6 \mathrm{~Hz}), 1.27$ (s., polymethylene), $1.60(3 \mathrm{H}, \mathrm{m}), 2.03,2.10,$.2.17 (3H each, s.), $2.97,3.50$ ( $1 \mathrm{H}$ each, s., OH). $4.50(1 \mathrm{H}, \mathrm{d} ., J=$ $12 \mathrm{~Hz}), 4.78(1 \mathrm{H}, \mathrm{d} ., J=2.5 \mathrm{~Hz}), 4.97(1 \mathrm{H}, \mathrm{d} ., J=10 \mathrm{~Hz})$, $5.07(1 \mathrm{H}, \mathrm{d} ., J=12 \mathrm{~Hz}), 5.22$ (1H, s.), 5.57 (1H, m.), $5.70(1 \mathrm{H}, \mathrm{m}$.$) .$

Acknowledgements. We are indebted to Mr. Akira Nagata and Mr. Kenji Takeda for collecting the sap of Hura crepitans. We wish to thank Dr. Tetsuro Shingu and Miss Mitsuko Okawa for the PMR, Mr. Tasuke Sakata for the IR and Mr. Akira Kato for the mass spectra measurements. Thanks are also due to Dr. Tamio Ueno for the combined gas chromatographymass spectrometry. 